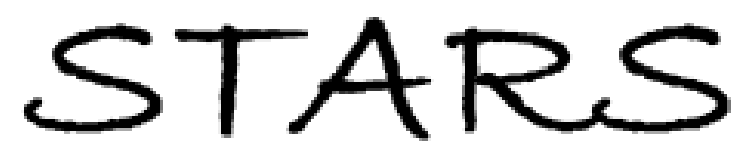

University of Central Florida

STARS

8-1-2012

\title{
Discounting Works in the Hotel Industry: A Structural Approach to Understanding Why
}

Robertico R. Croes

University of Central Florida, robertico.croes@ucf.edu

Kelly J. Semrad

University of Central Florida, Kelly.Semrad@ucf.edu

Part of the Hospitality Administration and Management Commons, and the Tourism and Travel Commons

Find similar works at: https://stars.library.ucf.edu/rosenscholar

University of Central Florida Libraries http://library.ucf.edu

This Paper is brought to you for free and open access by the Rosen College of Hospitality Management at STARS. It has been accepted for inclusion in Rosen Faculty Scholarship and Creative Works by an authorized administrator of STARS. For more information, please contact STARS@ucf.edu.

\section{Original Citation}

Croes, R. and Semrad, K. (2012). Discounting works. Tourism Economics 18(4), 769-780.

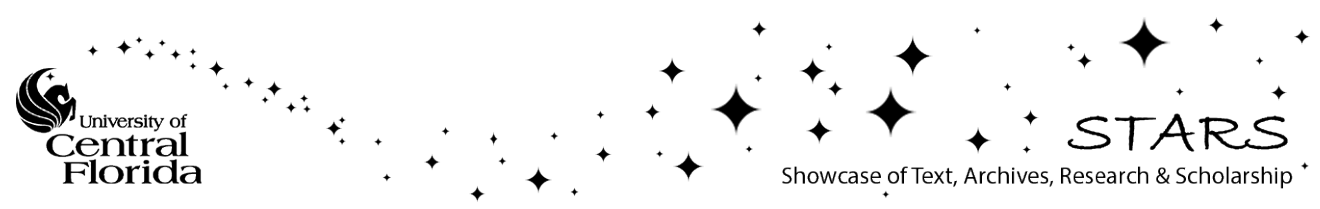




\title{
Discounting works in the hotel industry: a structural approach to understanding why
}

\author{
ROBERTICO CROES \\ Rosen College of Hospitality Management, University of Central Florida, 9907 Universal \\ Blvd, Orlando, FL 32819-9357, USA. E-mail: robertico.croes@ucf.edu.
}

KELLY J. SEMRAD

Eric Friedheim Tourism Institute, University of Florida, PO Box 118208, FLG \#242D, Gainesville,FL 32611, USA. E-mail: ksemrad@hhp.ufl.edu.

(Corresponding author.)

\begin{abstract}
This case study provides an empirical assessment of the relationship between discounting hotel room rates and hotel financial performance. The dynamics of the lodging industry are accounted for through the adoption of an error correction model. Recent research suggests that the use of discounting room rates may not be an effective pricing strategy as it results in increased occupancy rates at decreased average daily rates, thereby reducing a common financial performance indicator - revenue per available room (revPAR). The recommendation made to hotel managers, then, is to avoid discounting and instead adopt an average rate. This study generates opposing findings and reveals that discounting may be a practical short-term pricing solution that may compensate for market disequilibria. The results suggest that using statistical residuals rather than room rate averages may more accurately forecast appropriate hotel room rates and balance supply and demand. Thus, the recommendation of adopting average room rates may provide incorrect implications for managers in the short run.
\end{abstract}

Keywords: hotels; discounting; room rates; residuals; error correction model

The hotel industry is a dynamic industry that is comprised of perishable products (Hanks et al, 2002; Van der Rest and Harris, 2008; Wheaton and Rossoff, 1998). It is a cause-effect industry that is given to fluctuations of financial performance caused by consumer needs, demands and product availability, thereby creating variability in performance that could be costly to business (Nicolau, 2005). As a result, hotel managers are charged with developing pricing strategies to offset the imbalances that a fluctuating market creates in terms of supply and demand. Principal to that imbalance is the lack 
of demand for hotel rooms during diminished demand seasons. Thus, as occupancy levels decrease, the supply of hotel rooms increases. In the process, hotel managers scramble to find a way to make up for the revenue lost in these low demand seasons and have long toiled over the courses of action that may best assist them in overcoming the challenges of preserving hotel revenue during such periods (Canina and Enz, 2006; Chan and Wong, 2006; Gayar et al, 2007; Van der Rest and Harris, 2008).

A commonly adopted pricing strategy to overcome this challenge is the discounting of hotel room rates to sustain revenue (Donaghy et al, 1995). That revenue would otherwise be lost, with the supply of rooms exceeding demand (Brown and Dev, 1999). Hotel managers therefore require a procedure to aid them in solving hotel occupancy problems that could threaten revenue during low occupancy seasons. The prominent procedure suggested in the lodging literature is the application of averages (room rates and occupancy levels) to forecast room rates and revenues (Canina and Enz, 2006; Chan and Wong, 2006; Enz et al, 2009; Enz et al, 2004). This strand in the literature rejects discounting room rates as an effective pricing strategy.

This case study departs from previous studies in that it assumes that irregular behaviour, rather than averages, provides a richer source of information from which clues may be extracted from the data to determine a hotel's optimal room rate. Therefore, it is suggested that the application of the error correction model provides a more meaningful technique for hotel managers than the use of averages to forecast room rates and revenues. The aim of the study is to analyse the magnitude and significance of the relationship between room rate discounting and hotel financial performance, and to determine whether the nature of this relationship is linear or non-linear, or positive or negative.

The study does not focus on the determinants of financial performance. Rather, it is assumed that the historical room rates and financial performance from the time series data set contain stored information that is reflective of past latent variables that may have shocked the series (such as competition, consumers' willingness to pay, etc). Such shocks may adjust the average behaviour of managers; however, the use of an error correction model assists in the detection of adjustment in behaviours. In other words, the incorporation of deviations (that is, statistical residuals) captures compressed market information that may have influenced the variables in the series. Therefore, historical room rates are considered to be a sound predictor of financial performance.

\section{Explaining discounting}

Traditionally, managers have responded to the challenge of restoring lost revenue by engaging in discounting strategies. The discounting process involves a short-term offering of a room rate that is below the premium rate. Managers calculate the discounted rate by identifying the occupancy level necessary to hold the total revenue, less marginal costs, constant after the average daily rate of a room has been discounted (Schwartz and Cohen, 2003). Here, the manager's objective is to increase hotel financial performance by bringing the market back to equilibrium. This equilibrium translates to a hotel room rate that balances 
supply and demand (Sezen, 2004). The question is, does discounting room rates help facilitate this balance?

Because occupancy rates are a key factor in hotel financial performance (Brown and Dev, 1999), discounting could be used as a short-term pricing strategy to generate revenue through the sale of a hotel's room nights. Because room nights are perishable products, managers recognize that the value of a room night becomes zero if it is not sold by a specific time (Cross et al, 2009; Finch et al, 1998). Therefore, discounting may inflate a low occupancy percentage and increase hotel financial performance during low demand seasons (Jeffrey et al, 2002).

The literature has been critical about discounting (Canina and Enz, 2006; Chan and Wong, 2006; Cross et al, 2009; Enz, 2009; Enz, 2003; Enz and Canina, 2007; Enz et al, 2008; Enz et al, 2009; Enz et al, 2004). Studies imply that discounting entails losing money (or potential revenue) and suggest instead the use of average prices. These prescriptions rely on two sets of arguments: (a) lost revenue due to discounting is not compensated by an increase in the volume of sales (occupancy), and (b) it takes a long time to recover from rate reductions, and therefore securing price integrity is crucial to a hotel's profitability. This study takes issue with these arguments in two ways.

First, average behaviour of managers could make sense only in the long run, because outcomes that result from expectations do not necessarily confirm and conform to those expectations. Even if all hotel managers share the same motivation (maximizing profits), and if all expect the same average behaviour (do not discount), they will systematically displace the average from where they thought it would be. Hotel managers will make allowance for everybody else's bias and adjust their performance, which then further aggravates the displacement. Consider a manager who wants to earn a little above the industry average. $\mathrm{He}$ or she raises the room price, other hotel managers follow suit, and the pattern of increasing prices above those of competitors continues until the prices stabilize and no one can afford to earn above the average. What one manager does will affect what other managers do. Therefore, the degree of quality with which each manager accomplishes his or her financial goal becomes dependent on what others are doing.

Second, even if managers have complete information and trust in each other, outcomes may still deviate from expectations because the individual abilities of managers to adjust to the market conditions may vary. Thus, some managers may make compensating adjustments more readily than others. The consequence of this uneven distribution of ability is a kind of flip-flopping in pricing, which some commentators refer to as a 'bazaar' kind of behaviour (Hanks et al, 2002). A problem then transpires as to how to forecast optimal room prices under the condition of uncertain market demand conditions.

\section{Setting room rates}

The oscillating room demand patterns pervasive in the lodging industry make hotel managerial pricing decisions subject to risk and uncertainty that may lead to more than one explanation about revenue outcome (Choy, 1985; Gayar et al, 2007). One possible method that managers may use to set prices is based on 
instinct. For example, a manager may have developed 'rules of thumb' for pricing a hotel room to measure performance - those rules of thumb may incorporate years of experience, common-sense best practices, or even 'gut feeling'. However, gut feeling and common-sense practice may not work in an increased competitive setting and in the context of a volatile demand pattern. In addition, it would be difficult to establish behavioural patterns and, therefore, impossible to learn from regularities in behaviour other than that common sense or instinct was used to set prices. This tacit knowledge would be difficult to convert into organizational knowledge.

Another technique explaining price setting behaviour is the use of historical averages of room rates to forecast viable future room rates. This practice identifies the application of averages as a more secure method than simply forecasting room sales and demand based on gut feeling and instinct. Researchers who conclude that using an average room rate is the best practice for pricing of hotel rooms base their claim on a commonly expressed complaint of some hotel managers: 'We have occupancy now but not an average room rate!' This strand of analysis, like 'gut feeling', also rejects discounting as a viable way to price room rates. This perspective contends that, despite an increase in occupancy rates, the hotel still suffers from a decrease in revenue per available room (revPAR) (Canina and Enz, 2006; Chan and Wong, 2006; Enz et al, 2009; Enz et al, 2004).

Yet, managers may still have erred in pricing in the short term because correlative perspectives regarding the relationship between room rates and financial performance have guided them in their pricing decisions. The ability to use correlations depends on the relationship between variables and whether this relationship remains relatively stable over time (Banerjee et al, 1993), a condition that is not evident in the price setting process of the hotel industry. Some of the familiar challenges to setting room rates are the availability of the hotel's fixed capacity of rooms, the perishability of the product (room night), the high fixed costs of operation and the seasonal imbalance between a hotel's room supply and demand (Donaghy et al, 1995; Van der Rest and Harris, 2008).

Another plausible method of price setting behaviour is for managers to discount regularly from their set rack rates (Boger et al, 1999). Rack rates are set based on cost plus a mark-up without taking into account the price elasticity of demand. Here, managers are not likely to be able to charge those rates, resulting in constant price adjustments to respond to demand changes.

\section{A structural explanation for pricing behaviour}

Managers may routinely use the room rate of the immediate past to forecast the appropriate room rate for the future. This means that they typically assume that present market conditions will behave similarly to those of the past. Analysis of past historical data leads the manager to expect that a short-term discounting pricing strategy may guarantee that long-term strategies will yield long-term revenue and profit growth. This means that there appears to be an action-reaction dynamic that operates through discounting in the short term and is displayed as a long-term interaction between discounting and financial performance. This approach recognizes that an equilibrium price exists when 
the supply of hotel rooms in a given market equals the consumer demand for hotel rooms in the same market. This may be true in the long term but not in the short term, because of the oscillating uncertainties of demand that is prevalent in seasonality. This means that prices rise when demand is strong and prices fall when demand is weak (Levin et al, 2005).

Such an expectation seems appropriate for the hotel industry because the inventory of hotel rooms cannot be stored like that of tangible goods. In truth, a hotel room represents a product that is close to a 'pure service' (Van der Rest and Harris, 2008). That is, if the room night goes unsold, the revenue of the room is lost and its possible contributions to high fixed overhead costs are also lost (Finch et al, 1998). Therefore, when the demand for hotel rooms is weak (low season), it may be in the best interest of hotel managers to implement a short-term discounting strategy based on historical seasonal room rates that will sell the room and include a profit, as well as covering the variable cost associated with serving that room.

Purportedly, using averages and maintaining price integrity could be a dangerous position. The use of averages assumes that the revenue outcome of a month is completely independent of the previous month. But this independence assumption does not seem to conform to a manager's behaviour. Managers know that, when occupancy falls short of expectations, they cannot make adjustment through room supply in the short term. So, the only possible option for adjustment in the short term is price setting (Cross et al, 2009; Cross, 1997). Managers typically take the price outcome of a present time period and continue it into the future. Therefore, they seem to take the past into account and thus violate the independence assumption made by those who espouse the use of average prices.

In other words, studies that do not support the use of discounting may be biased, because researchers who encourage the use of an average room rate instead of a discounted room rate may not have assessed properly the statistical properties that a time series data set assumes in order to establish that a 'causeand-effect' relationship between discounting and hotel financial performance exists. As the future is not the same as the past, they err in setting the price. As a result, the managers begin the seasonal price adjustment process of hotel rooms in an effort to determine the room rates that will insure the most rooms at the greatest profit (Levin et al, 2005). In reality, the concept behind room rate pricing is similar to setting a thermostat on an air conditioning unit. Past average temperatures have no relevance to setting the thermostat temperature today. Instead, the thermostat is a mechanical process that adjusts to the present environmental conditions of heat. Likewise, hotel room rates are dependent on the present conditions of seasonality.

The forecasting of seasonal consumption should not assume that a purportedly linear function over time is hidden in average price setting (Juselius, 2008). This is because of the perishable nature of the available room inventory: it cannot expand or contract according to the seasonal demand spikes and plummets (Corgel, 2004; Hanks et al, 2002). The use of averages to set room prices may be an appropriate strategy when supply and demand are in balance, but it is most likely an ineffective strategy when the market is in a state of disequilibrium.

The potential managerial consequences of the continued implementation of 
the average price approach during the industry's volatile demand cycles could result in an inflation of room rates for which the market is not willing to pay. This pricing error may then result in the loss of potential revenue that could negatively affect the overall financial performance of the hotel. The problems that the use of averages could produce arise because averages cannot distinguish between temporary and permanent relationships among variables in a dynamic setting (for example, variables with a trend). To represent the dynamics of a time series data set in the hotel industry more accurately, it is better to focus on statistical residuals as a source of pricing behaviour.

\section{Methodology}

This study is founded on two assumptions: first, that deviations in behaviour may provide a richer source of information than averages to set room rates, and, second, that hotel managers are more likely first to use readily available information (historical room rates) than to acquire external information in the formation of their pricing strategy for a given period. This means that managers may first formulate their prices based on past expectations and performance and then may confirm the pricing strategy with external sources of information. Based on these assumptions, a parsimonious model was designed to assess the nature of the relationship between discounting and hotel financial performance.

Arguably, in positing a simple bivariate model, the study may have omitted other important market factors and conditions that could be influencing the variables and the relationship between them. Therefore, in order to incorporate the potential influence of market factors in the model, statistical residuals were integrated and treated as a second predictor variable. Thus, the other important latent factors that may be influencing the relationship between the variables were adopted through the use of residuals, which observe deviations in behaviour which are assumed to be instigated by past market conditions. This means that other determinants of financial performance were not directly considered as measurement errors, but were indirectly included and addressed through the use of statistical residuals as a variable in the model. The residuals were then postulated as proxies for the disparities driving room rates and performance. Use of the error correction model enabled us to assess whether the incorporation of residuals assisted in the formation of a more accurate room rate prediction.

The study used three years of monthly historical financial data (2005-07) from one of the largest convention hotels in Orlando, Florida. The data set contained the following data points: monthly demand, monthly available rooms, premium room rates, actual room rates, occupancy rates, department profit, monthly rooms compensated for employees, monthly rooms occupied by reward programme members, and total hotel profit contributed by guests (hotel financial performance). For the purposes of this study, discounting is defined as the short-term offering of a room rate below the premium rate. Hotel financial performance is measured by profit per available room (profitPAR) rather than by using revPAR.

The benefit of using profitPAR as a unit of measurement is that it provides a more accurate indication of financial performance than the traditional unit 
Table 1. Unit root tests on LogFinPerf and LogDisc.

Variables

ADF levels

ADF first differences

PP levels

PP first differences

LogFinPerf

$$
-3.941^{*}
$$

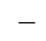

$-3.965$

LogDisc

$-2.362$

$-2.571$

$\triangle$ LogFinPerf

$\Delta \log$ Disc

$-$

$-$

$-5.556^{*}$

$-4.405^{*}$

Note: Estimates are obtained from STATA Version 9 and correspond to 36 observations. $\Delta$ indicates the first differencing of the variables. The ADF tests should be compared to the critical values of -2.619 , -2.975 and -3.689 and the PP tests at $-2.619,-2.975,-3.689$ at the $10 \%, 5 \%$, and $1 \%$ levels of significance, respectively. ${ }^{*}$ Denotes statistical significance at the $1 \%$ level.

of measurement, revPAR. This is because profitPAR includes all revenue and marginal costs contributed by the guests to the hotel's revenue-producing operating departments. In order to clean the data, the two variables, discounting and financial performance, were disaggregated to remove the rooms sold and the profit from those rooms that were offered at an inflated discounted rate to hotel employees and reward programme members. Then the data of the two variables were converted into natural logarithms to create parameter elasticities that are more comprehensible.

It is understood that a manager could set appropriate price adjustments and estimates to account for non-stationarity conditions (high and low demand seasons) with the detection of data trends that indicate whether a variable is dependent on the previous values of that variable (Kulendran and Divisekera, 2007). This statistical implication confirms whether or not historical data points 'hold memory'. Time series data sets that hold memory are said to have a unit root. A unit root may cause serial correlation problems that may be resolved by including a number of lags to the time series data set. The number of lags is determined through a series of statistical tests and then tested via the augmented Dickey-Fuller (ADF) test and the Phillips-Perron (PP) test.

The ADF and PP tests statistics were compared with the critical value at the $5 \%$ level of significance. In the case of this hotel, the time series data set revealed that the discounting variable contained a unit root. Essentially, this means that a previous discounting data point (fiscal period) may be used to predict the next fiscal period's discounted rate. A unit root may mean two things: (a) in the short run there is a constant adjustment process that may err on the room price and produce biased estimates of the equilibrium relationship between variables, and (b) in the long run discounted rates could return to a long-term mean regardless of the increase or decrease in seasonal demand. Using the first difference of the data, it was evident that the data attained stationarity, and the ADF statistics were less than the critical value at the $1 \%$ level significance. The results are reported in Table 1.

Managers may like to know how long these short-run and long-run processes (price adjustments) will take. In order to determine if discounting and financial performance will converge, or attain equilibrium over time, managers may use a cointegrated VAR model. The findings from the cointegration analysis validated the recommendation to analyse the variables further within the time 
series data set by using an error correction model. The purpose of the error correction model is to ascertain whether discounting and financial performance have both a long-term and a short-term relationship. The long-term relationship equated to $Y=0.118 X(t=8.58 ; p>0.000$; and $\mathrm{DW}=2.182)$. However, these values do not represent a complete picture of this specific consumption behaviour and the relationship between the variables. The results also reveal that there is an adjustment process that takes place in this particular behaviour which is captured by a correction mechanism driving the price of a room to an equilibrium point.

This correction is the error correction (EC), where the $\mathrm{EC}=Y-0.961 X$ $(t=-6.08)$. Because the EC is non-zero $(-0.961)$, it provides an indication that the model is in a state of disequilibria and may adjust to the discounting variable with a lag. Approximately $96 \%$ of the discrepancy between long-term and short-term profits is corrected for after one month. The short-term coefficient $(0.132)$ is larger than the long-term coefficient $(0.118)$, suggesting that the relationship between discounting room rates and financial performance is concave. This means that the effects on performance of discounting room rates may seem steep in the beginning and later to flatten or dilute.

\section{Findings and discussion}

A practical implication of this study is that managers may use short-term discounting as a means to increase hotel financial performance. Further, in the case of the hotel examined, it was found that it was possible for a hotel manager to use the hotel's historical financial data for a little more than 30 days from any given fiscal period to forecast the effects of a discounted room rate on hotel financial performance. However, after approximately 30 days, the effects of discounting may become diluted in the data set and it may no longer be detected as having an effect on financial performance. The results reveal that the effect of discounting on financial performance quickly dilutes from the data. This may be due to the conditions of the seasonal demand shifts in the market in Orlando, where one period includes a low demand month immediately followed by a high demand month. For example, according to the Orange County Convention \& Visitors Bureau (2007), August is recognized as a relatively low demand month for Orlando hotels, but September is a relatively high demand month. The speed of the dilution of discounting in the data set seems to follow suit with the market conditions of Orlando.

This study has proposed a more practical industry approach to the implementation of discounted room rates in keeping with diminished demand. Trend analysis (the error correction model) determined that hotel managers might use historical financial data to establish the upper and lower price bands that act as indicators of seasonal financial performance. The price bands may provide critical limits of the expected effects of discounting on hotel financial performance. While a manager may err in the pricing of a room by deviating from appropriate seasonal rates, price bands may allow him or her to readjust the optimal room rate in the short run.

Although the manager may err in the pricing of a room by going over or under the suitable seasonal rate, the use of the upper and lower price bands 
creates a self-adjusting optimal room rate in the short run which is likely to result in an increased hotel financial performance during weak demand conditions. The use of averages assumes that past performance is not important. Averages further assume that managers do not employ their knowledge about which pricing strategies worked in the past and how those strategies could assist them in the preparation of uncertain seasonal demand conditions in the future.

In the short term, it is not recommended that averages are used to set room rates in the hotel industry. The structural characteristics of the industry impede such a strategy: demand response is unclear, the elasticity of demand for the supply of rooms is not constant, and the rooms are perishable. Managers know and understand these characteristics, but may not always choose, or may be illadvised about the most appropriate strategy to use to set room rates. This study contends that managers may use the immediate past to formulate room rates, and that the use of the error correction model may enable them to enhance their revenue expectations. For example, through the use of an error correction model, a hotel manager may determine how much extra revenue may be generated in a specific period. In the particular case examined in this article, the hotel management may observe that an increase of $10 \%$ in discounting may quickly assist in the correction for disequilibria and also that it dilutes quickly from influencing future room rates. In addition, the managers may determine what the expected revenues might be without the use of discounting as a pricing strategy.

\section{Implications and conclusions}

The results of this study are unique in that the research recognizes the challenges of the industry's dynamics as they affect discounting pricing decisions, and addresses the 'how to' pricing concerns of hotel managers. Importantly, the findings are empirically supported through a more rigorous statistical assessment than the use of average room rates. The high explanatory power of the statistical techniques used in this study, specifically the use of the error correction model, suggests that the study may hold high internal validity. However, the results are based on a case study design, thereby compromising their external generalizability.

Nevertheless, it is anticipated that future studies which follow the methodological framework provided may produce similar results, as the statistical procedures applied did more than assess the common industry trend. The cointegration analysis revealed a relationship property in the data set between the discounting and hotel financial performance variables which should hold in a larger data set, given that a cointegrated relationship is invariant to changes (Juselius, 2008; Kulendran and Divisekera, 2007).

An additional limitation of the study is that it has assessed only the impact of historical room rates on financial performance. Other important factors that may have influenced the time series were treated as latent factors. The influences of additional latent factors were incorporated into the model in the form of statistical residuals. The results indicated that the omitted factors could act as an error correction mechanism that will push and pull the variables into a cointegrating relationship over time. However, the inability to specify what 
these latent factors may be, such as competition and value-based pricing reflecting consumers' willingness to pay, is a limitation of the study.

While the use of price averages may reflect some trend in consumption, it does not reveal the whole picture. Pricing decisions based on averages may prove to be less than optimal for seasonal market conditions. The error correction model could provide superior accuracy for how to price a hotel room rate accordingly, so as to avoid the potential loss of a room sale perishing. The error correction model has this capability because of the use of residuals in the model that takes into account the effects of omitted information (variables) (Juselius, 2008). Thus, as seasonal demand shocks occur in the hotel industry, managers of a single hotel may expect that a state of disequilibria may occur; but that the adjustment coefficient will force the pricing process back towards the attractor set (price bands or tolerable price limits) with an adjustment speed that would depend on the length and size of the equilibrium error. This would provide managers with critical information regarding when and for how long they should discount room rates.

The study offers a new contribution to research in that the error correction model has not previously been applied to determine the relationship between discounting and hotel financial performance. The study provides managers with pricing insight to aid in maximizing hotel revenues by focusing on residuals rather than price averages as units of analysis. The main implication of the research is that, regardless of the simplicity of the hotel's pricing strategies, the statistical sophistication required to establish appropriate prices in the hotel market should not be compromised. The use of residuals over averages is important because residuals reveal patterns in the data that enable significant discoveries in the data set which may indicate other influencing factors that need to be taken into account (Banerjee et al, 1998). The suggestion arising from this study is that residuals should be treated as an observed variable in its own right to assist in the forecasting of appropriate hotel room rates.

\section{References}

Banerjee, A., Dolado, J., Galbrath, J., and Hendry, D. (1993), Co-integration, Error-Correction, and the Econometric Analysis of Non-Stationary Data, Oxford University Press, New York.

Boger, C., Liping, A., and Lin, L. (1999), 'Benchmarking: comparing discounted business rates among lodging companies', Journal of Hospitality \& Tourism Research, Vol 23, No 3, pp 256-267.

Brown, J., and Dev, C. (1999), 'Looking beyond revPAR', Cornell Hotel and Restaurant Administration Quarterly, Vol 40, No 2, pp 23-31.

Canina, L., and Enz. C. (2006), 'Why discounting still doesn't work: a hotel pricing update', Cornell Hospitality Reports, Vol 6, No 2, pp 5-22.

Chan, E., and Wong, S. (2006), 'Hotel selection: when price is not the issue', Journal of Vacation Marketing, Vol 12, No 2, pp 142-159.

Choy, D. (1985), 'Forecasting hotel-industry performance', Tourism Management, Vol 5, No 3, pp 171176.

Corgel, J. (2004), 'Focus on hospitality: predictive powers of hotel cycles', Real Estate Issues, Vol 28, No 4, pp 32-36.

Cross, R. (1997), 'Launching the revenue rocket', Cornell Hotel and Restaurant Administration Quarterly, Vol 38, No 2, pp 32-43.

Cross, R., Higbie, J., and, Cross, D. (2009), 'Revenue management's renaissance: a rebirth of the art and science of profitable revenue generation', Cornell Hospitality Quarterly, Vol 50, No 1, pp 56-81.

Donaghy, K., McMahon, U., and McDowell, D. (1995), 'Yield management: an overview', International Journal of Hospitality Management, Vol 14, No 2, pp 139-150. 
Enz, C. (2009), 'Key issues of concern in the lodging industry: what makes managers worry', Cornell Hospitality Reports, Vol 9, No 4, pp 5-16.

Enz, C. (2003), 'Hotel pricing in a networked world', Cornell Hotel and Restaurant Administration Quarterly, Vol 44, No 1, pp 4-6.

Enz, C., and Canina, C. (2007), 'Pricing for revenue enhancement in Asian and Pacific Region hotels: a study of relative pricing strategies', Cornell Hospitality Reports, Vol 8, No 3, pp 4-18.

Enz, C., Canina, L., and Liu, Z. (2008), 'Competitive dynamics and pricing behavior in US hotels: the role of co-location', Scandinavian Journal of Hospitality and Tourism, Vol 8, No 3, pp 230250.

Enz, C., Canina, L., and Lomanno, M. (2009), 'Competitive pricing decisions in uncertain times', Cornell Hospitality Quarterly, Vol 50, No 3, pp 325-341.

Enz, C., Canina, L., and Lomanno, M. (2004), 'Why discounting does not work: the dynamics of rising occupancy and falling revenue among competitors', Cornell Hospitality Reports, Vol 4, No 7, pp 5-25.

Finch, J., Becherer, R., and Casavant, R. (1998), 'An option-based approach for pricing perishable services assets', Journal of Services Marketing, Vol 12, No 6, pp 473-483.

Gayar, N., Hendawi, A., and Shishiny, H. (2007), 'A proposed decision support model for hotel revenue management', Data Mining and Computer Modeling Center of Excellence, Cairo.

Hanks, R., Cross, R., and Noland, P. (2002), 'Discounting in the hotel industry: a new approach', Cornell Hotel and Restaurant Administration Quarterly, Vol 43, No 4, pp 94-103.

Jeffrey, D., Barden, R., Buckley, P., and Hubbard, N. (2002), 'What makes for a successful hotel? Insights on hotel management following 15 years of hotel occupancy analysis in England', Service Industries Journal, Vol 22, No 2, pp 73-88.

Juselius, K. (2008), The Cointegrated VAR Model: Methodology and Applications, Oxford University Press, New York.

Kulendran, N., and Divisekera, S. (2007), 'Measuring the economic impact of Australian tourism marketing expenditure', Tourism Economics, Vol 13, No 2, pp 261-274.

Levin, Y., McGill, J., and Nediak, M. (2005), 'Optimal dynamic pricing of perishable items by a monopolist facing strategic consumers', Working Paper, School of Business, Queen's University, Kingston, Ontario.

Nicolau, J. (2005), 'Leveraging profit from the fixed-variable cost ratio: the case of new hotels in Spain', Tourism Management, Vol 26, No 1, pp 105-111.

Orange County Convention \& Visitors Bureau, Inc (2008), Convention/Group Meeting Visitor Profile, Annual Financial Report, Orange County Convention \& Visitors Bureau, Orlando, FL.

Schwartz, Z., and Cohen, E. (2003), 'Hotel revenue management with group discount room rates', Journal of Hospitality \& Tourism Research, Vol 27, No 1, pp 24-47.

Sezen, B. (2004), 'Expected profit approach used in discount pricing decisions for perishable products', International Journal of Retail and Distribution Management, Vol 32, No 4, pp 223-229.

Van der Rest, J., and Harris, P. (2008), 'Optimal imperfect pricing decision-making: modifying and applying Nash's rule in a service sector context', International Journal of Hospitality Management, Vol 27, No 2, pp 171-178.

Wheaton, W., and Rossoff, L. (1998), 'The cyclic behavior of the US lodging industry', Real Estate Economics, Vol 26, No 1, pp 67-82. 